\title{
Alpha-1-antitrypsin Pi S phenotype and liver cell inclusion bodies in alcoholic hepatitis
}

\author{
J. K. KELLY ${ }^{1}$, T. V. TAYLOR ${ }^{2 *}$, AND A. MILFORD-WARD ${ }^{3}$
}

From the ${ }^{1}$ Department of Pathology, Stopford Building, University of Manchester; the ${ }^{2}$ Department of Surgery, Manchester Royal Infirmary; and the ${ }^{3}$ Supraregional Protein Reference Unit, Hallamshire Hospital Medical School, Sheffield, UK

SUMMARY Typical liver cell inclusions of alpha-1-antitrypsin deficiency were found in a patient with the Pi S phenotype and acute alcoholic hepatitis. It is suggested that the inclusions resulted from the combined effects of the $S$ phenotype and alcohol and, on the basis of the known chemistry of the variant antitrypsins, that the lowered serum concentration of antitrypsin associated with the $\mathrm{S}$ allele may be due to hepatic holdup.

Globular inclusions of alpha-1-antitrypsin (AAT) may be found in hepatocytes of individuals bearing the Pi Z allele (Sharp, 1971; Gordon et al., 1972) and in carriers of the Pi M Duarte and Pi M Malton alleles (Cox, 1976; Lieberman et al., 1976). Globules have been described in one $\mathrm{Pi} \mathrm{S}$ homozygote (Lieberman et al., 1972) but this case was subsequently found to be Pi SZ (Cook, 1976, quoted by Bradfield and Blenkinsopp, 1977). Fisher et al. (1976) found globules in three $\mathrm{Pi}$ MS individuals but neither photographs nor details of the cases were given. This report documents the presence of intrahepatocytic AAT globules in the liver of a man with the Pi S phenotype and alcoholic hepatitis.

\section{Case report}

An alcoholic man aged 56 years, who had consumed more than one bottle of spirits per day for many years, complained of weight loss, anorexia, diarrhoea, and fatigue of one year's duration. He was a chronic bronchitic and was admitted to hospital because of abdominal swelling. On examination spider naevi, a tinge of jaundice, ascites, and hepatomegaly were present. Investigations revealed: $\mathrm{Hb} 15.1 \mathrm{~g} / \mathrm{dl}$, WCC $13 \times 10^{y} / 1$, ESR $30 \mathrm{~mm} / \mathrm{h}$, alkaline phosphatase $181 \mathrm{IU} / 1$, SGOT $152 \mathrm{IU} / \mathrm{l}$, and bilirubin 37 $\mu \mathrm{mol} / \mathrm{l}$. Barium meal was normal. A barium enema showed diverticular disease. An isotope liver scan showed an enlarged liver with poor uptake along

*Present address: Department of Clinical Surgery, The Royal Infirmary, Edinburgh

Received for publication 2 January 1979 the inferior border and along the upper aspect. The spleen was of normal size. At laparotomy there was considerable ascites. The liver was greatly enlarged and nodular. A biopsy was taken and a diagnosis of alcoholic hepatitis and cirrhosis was made. Serum AAT determined as an outpatient was $0.9 \mathrm{~g} / 1$ (normal 1.8-3.0 g/l), the phenotype being Pi S. His condition remained unchanged after discharge until he died suddenly at home five months after discharge from hospital, and a coroner's necropsy was performed. The cause of death was recorded as bronchopneumonia due to cirrhosis of the liver.

\section{Material and methods}

Sections ( $5 \mathrm{mu}$ ) of formalin-fixed, paraffin-embedded liver were stained with haematoxylin and eosin, PAS after diastase digestion, Masson Trichrome, and the Gordon-Sweet reticulin stains. Sections for immunoperoxidase staining were mounted on slides subbed with chromalum-gelatin.

\section{IMMUNOPEROXIDASE TECHNIQUE}

The method was essentially that of Sternberger $\mathrm{et}$ al. (1970). Commercial antisera were used: Rabbit antihuman alpha-1-antitrypsin (R-AAT) (Dakopatts and Behringwerke); swine antirabbit IgG (SWAR); and peroxidase-rabbit-anti-peroxidase complexes (PAP) (Dakopatts). The batches of R-AAT gave a single precipitin arc on immunoelectrophoresis against normal human sera.

Sections were dewaxed in xylene and transferred to methanol containing $0.3 \%$ hydrogen peroxide for 30 minutes to block endogenous peroxidase 706 
activity. They were washed and covered with $1 / 10$ normal swine serum for 15 minutes. The swine serum was decanted, and the sections were treated sequentially with R-AAT, SWAR, and PAP for 40,20 , and 20 minutes respectively. Between incubations the sections were washed. All dilutions of sera and all washing procedures were performed

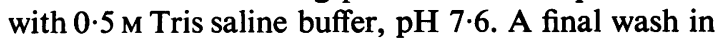
$0.05 \mathrm{M}$ Tris buffer, $\mathrm{pH} 7.6$, was followed by staining on $0.05 \mathrm{M}$ Tris buffer, $\mathrm{pH} 7.6$, containing $30 \mathrm{mg} / 100$ $\mathrm{ml}$ of $3,3^{\prime}$ diaminobenzidine tetrahydrochloride with $0.01 \%$ hydrogen peroxide for 10 minutes (Graham and Karnovsky, 1966). Specific staining was identified by deposition of the brown reaction product. The reaction was stopped by immersion in distilled water. Sections were counterstained lightly with Harris' haematoxylin.

\section{CONTROLS}

Control sections were stained in parallel with the following modifications:

1 The primary antiserum was replaced by normal rabbit serum.

2 The SWAR was replaced by normal swine serum.

3 The primary antiserum was absorbed with purified AAT.

\section{AAT quantitation and phenotype}

Quantitative analysis of serum AAT was performed by automated immunoprecipitation. The Pi phenotype was identified by isoelectric focusing in polyacrylamide gel (Ward et al., 1977).

\section{Results}

\section{HISTOLOGY}

There was moderate fatty change; hepatocytes were swollen; abundant Mallory's hyaline was present (Fig. 1) and there were occasional giant mitochondria. There were many focal areas of neutrophil polymorphonuclear cell infiltration, particularly in relation to the hyaline-containing cells. Centrilobular hyaline fibrosis, pericellular creeping fibrosis, and bridging of centrilobular to portal areas with nodule formation were present. Portal areas were expanded and inflamed and showed variable bile duct proliferation. The appearances were those of acute alcoholic hepatitis with cirrhosis. Intrahepatocytic, PAS-positive, diastase-resistant globules were present focally beside portal areas.

IMMUNOPEROXIDASE

On immunoperoxidase preparations the globules

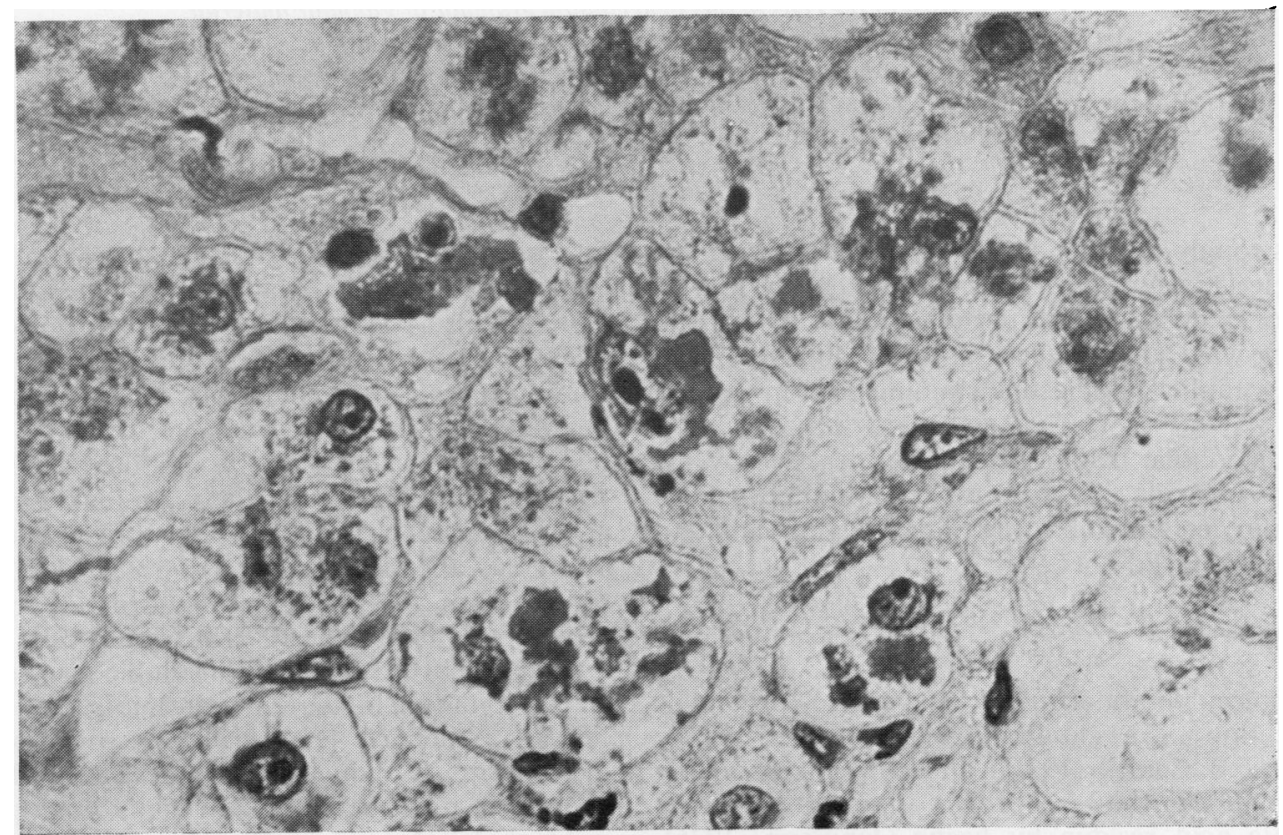

Fig. 1 Several hydropic cells in centre of field contain irregular clumps of eosinophilic Mallory's hyalin. (Haematoxylin and eosin $\times 650)$ 


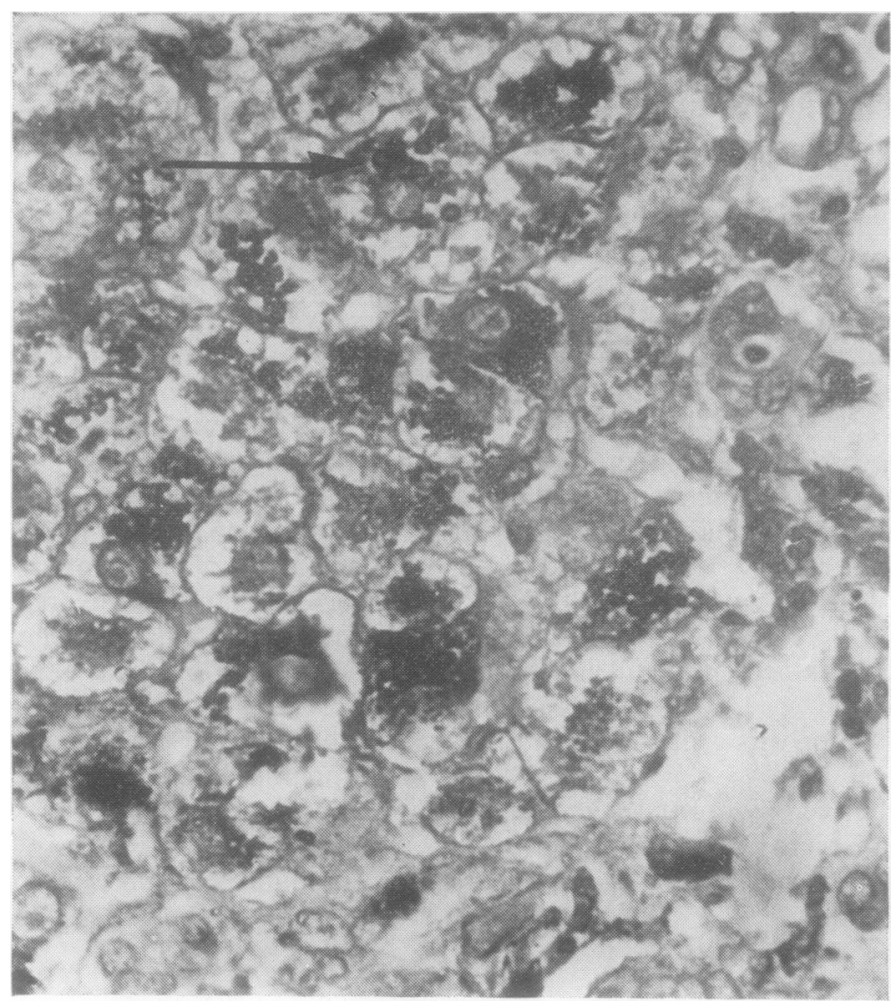

Fig. 2 Most of the cells in this field contain granular or globular material, which stains positively for alpha-1-antitrypsin (black). The larger, globular bodies show the characteristic rim staining (arrow) while the granular material stains homogeneously. (Immunoperoxidasehaematoxylin $\times 650$ )

were strongly stained, the larger ones showing the characteristic darker peripheral staining rim (Fig. 2). Control sections were negative. The pattern of staining was quite distinct from the diffuse or very finely granular cytoplasmic staining seen in normal livers.

The alcoholic hyalin was totally negative by the immunoperoxidase technique. The binding of PAP by hyalin encountered using unfixed tissue (Sim and French, 1976) did not occur.

\section{Discussion}

The molecular abnormality in the $\mathrm{Pi} S$ protein is substitution of a glutamic-acid residue by valine (Owen and Carrell, 1976), and the corresponding abnormality in the Pi $\mathrm{Z}$ protein is substitution of a glutamic acid residue by lysine (Jeppsson, 1976). Lysine is a basic amino-acid and valine is neutral; thus there is one charge unit difference between the
$\mathbf{P i} \mathbf{S}$ and $\mathbf{P i} \mathbf{M}$ proteins and two charge units difference between the $\mathrm{Pi} Z$ and $\mathrm{Pi} M$. The substituted glutamic acid residue in each of these proteins is in the same cyanogen bromide peptide (Jeppsson, 1976). Thus the molecular change in the $\mathrm{Pi} \mathrm{S}$ protein is qualitatively similar to that in the $\mathrm{Pi} Z$ protein but of lesser magnitude. The globular inclusions of partially glycosylated $\mathbf{Z}$ protein are highly insoluble, and the insolubility is probably a direct result of the molecular abnormality (Jeppsson et al., 1975). The similarity of the molecular abnormality of the $S$ protein to that of the $Z$ protein suggests that the $S$ protein may be relatively insoluble also, resulting in precipitation in the endoplasmic reticulum at a certain undefined stage of glycosylation. The mechanism of reduced blood levels in the $\mathrm{Pi} S$ phenotype may therefore be hepatic holdup.

Alcohol enhances synthesis and diminishes the export of hepatic protein, possibly through an antitubulin action (Baraona et al., 1975 and 1977). 
The low serum level of antitrypsin for the Pi S phenotype in this patient may reflect diminished export.

The combination of the Pi S phenotype and heavy alcohol consumption probably contributed to the formation of the typical liver cell AAT inclusions of the type seen with the $\mathrm{Pi} Z$ gene in this case. It seems likely that the $S$ gene product may be relatively insoluble during its transit through the endoplasmic reticulum but seldom results in sufficient aggregation to produce globules of light microscopic dimensions. Electron microscopy on $\mathrm{S}$ gene carriers would probably detect such holdup if it occurs.

While it is conceivable that the presence of globular inclusions of AAT in the homozygous $S$ phenotype represents a new variant $S$ phenotype, we have no evidence in favour of that postulation.

We thank the Manchester Coroner for a copy of the necropsy report on this patient, and Dr James Fajumi for a gift of purified alpha-1-antitrypsin.

\section{References}

Baraona, E., Leo, M. A., Borowsky, S. A., and Lieber, C. S. (1975). Alcoholic hepatomegaly; accumulation of protein in the liver. Science, 190, 794-795.

Baraona, E., Leo, M. A., Borowsky, S. A., and Lieber, C. S. (1977). Pathogenesis of alcohol-induced accumulation of protein in the liver. Journal of Clinical Investigation, 60, 546-554.

Bradfield, J. W. B., and Blenkinsopp, W. K. (1977). Alpha-1-antitrypsin globules in the liver and PiM phenotype. Journal of Clinical Pathology, 36, 464-466.

Cox, D. W. (1976). A new deficiency allele of alpha1-antitrypsin: Pi M Malton. Protides of the Biological Fluids, 23, 375-378.

Fisher, R. L., Taylor, L., and Sherlock, S. (1976). Alpha1-antitrypsin deficiency in liver disease: the extent of the problem. Gastroenterology, 71, 646-651.

Gordon, H. W., Dixon, J., Rogers, J. C., Mittman, C., and Lieberman, J. (1972). Alpha ${ }_{1}$-antitrypsin accumulation in livers of emphysematous patients with $\mathrm{A}_{1} \mathrm{AT}$ deficiency. Human Pathology, 3, 361-369.

Graham, R. C. J., Jr., and Karnovsky, M. J. (1966). The early stages of absorption of injected horseradish peroxidase in the proximal tubules of mouse kidney: ultrastructural cytochemistry by a new technique. Journal of Histochemistry and Cytochemistry, 14, 291-302.

Jeppsson, J. O. (1976). Amino-acid substitution Glu $\rightarrow$ Lys in $a_{1}$-antitrypsin Pi Z. FEBS Letters, 65, 195-197.

Jeppsson, J. O., Larsson, C., and Eriksson, S. (1975). Characterization of alpha-1-antitrypsin in the inclusion bodies from the liver in alpha-1-antitrypsin deficiency. New England Journal of Medicine, 293, 576-579.

Lieberman, J., Gaidulis, L., and Klotz, S. D. (1976). A new deficient variant of alpha-1-antitrypsin (M Duarte): inability to detect the heterozygous state by antitrypsin pheontyping. American Review of Respiratory Disease, 113, 31-36.

Lieberman, J., Mittman, C., and Gordon, H. W. (1972). Alpha-1-antitrypsin in the livers of patients with emphysema. Science, 175, 63-65.

Owen, M. C., and Carrell, R. W. (1976). Alpha-1antitrypsin: molecular abnormality of $\mathrm{S}$ variant. British Medical Journal, 1, 130-131.

Sharp, H. L. (1971). Alpha-1-antitrypsin deficiency. Hospital Practice, 6, 83-96.

Sim, J. S., and French, S. W. (1976). Peroxidase-antiperoxidase complex: binding by Mallory bodies in unfixed tissue. Archives of Pathology and Laboratory Medicine, 100, 550-553.

Sternberger, L. A., Hardy, P. A., Jr., Cuculis, J. J., and Meyer, H. G. (1970). The unlabeled antibody enzyme method of immunocytochemistry. Journal of Histochemistry and Cytochemistry, 18, 315-333.

Ward, A. M., Pickering, J. D., Fagerhol, M. K., and Martin, J. P. (1977). Pi (antitrypsin) typing methods. Human Heredity, 27, 292-297.

Requests for reprints to: Dr James Kelly, Department of Pathology, University of Manchester, Stopford Building, Oxford Road, Manchester M13 9PT, UK. 